\title{
Coleção Dulce e João Carlos Figueiredo Ferraz: 0 espírito da nossa época ${ }^{1}$
}

\section{EMERSON DIONISIO GOMES DE OLIVEIRA}

\section{Resumo}

O presente texto busca compreender de que forma uma coleção pode ser instituída, interpretada e divulgada dentro da cultura curatorial hodierna. Para tanto, investigamos a coleção brasileira de Dulce e João Carlos Figueiredo Ferraz, configurada dentro dos códigos da arte moderna e contemporânea. Pesquisa que nos levou às narrativas sobre sua gênese, circulação e institucionalização por meio de estratégias operadas pelos mercados de arte, pelas táticas de comunicação expositiva e pela consolidação de uma instituição gestora: Instituto Figueiredo Ferraz. Instituição que administra a visibilidade da coleção por meio de projetos curatoriais pontuais.

Palavras-chave: coleção, curadoria, arte contemporânea 


\section{Dulce and João Carlos Figueiredo Ferraz’s art collection: the spirit of our time}

EMERSON DIONISIO GOMES DE OLIVEIRA

\section{Abstract}

This article investigates how an art collection can be established, interpreted and publicised within the modern curatorial culture. To this goal, we investigated the Brazilian collection of Dulce and João Carlos Figueiredo Ferraz, regulated within the codes of modern and contemporary art. The research opened up a perspective on the narratives of its foundation, circulation and institutionalisation through strategies operated by the art market, through the tactics of exhibition communication, and through the consolidation of an overseeing institution: Figueiredo Ferraz Institute, managing the visibility of the collection through well-timed

Keywords: curating projects. 


\section{Colección Dulce y João Figueiredo Ferraz: El espíritu de nuestra época}

\section{EMERSON DIONISIO GOMES DE OLIVEIRA}

\section{Resumen}

El presente texto intenta comprender de que manera una colección puede ser instituida, interpretada y divulgada dentro de la cultura de la curaduría hodierna. Para ello, investigamos la colección brasileña de Dulce y João Carlos Figueiredo Ferraz, representada dentro de los códigos del arte moderno y contemporáneo. Investigación que nos condujo a las narrativas acerca de la génesis, circulación e institucionalización de esta colección, llevada a cabo por estrategias operadas por los mercados de arte, por las tácticas de comunicación expositiva y por la consolidación de una institución gestora: Instituto Figueiredo Ferraz. Institución que administra la visibilidad de la colección según proyectos puntuales de curaduría.

Palabras clave: colección, curaduría, arte contemporáneo 


\section{O que define um "olhar" curatorial?}

É uma questão inquietante com respostas foram incessantemente debatidas nas últimas décadas ${ }^{2}$. Podemos arriscar como resposta provisória que uma "cultura da curadoria" já foi internalizada por parte considerável do sistema das artes visuais (MADZOSKI, 2014) neste século, em especial aquela parcela do sistema dedicado à produção considerada "contemporânea”. Tal cultura é responsável pela articulação dos significados que permeiam à arte, conferindo-lhes aspectos simbólicos ou metafóricos, e mesmo alegóricos. Seria, então, uma cultura das estratégias cênicas e discursivas que funcionam como elo entre tantas outras estratégias narrativas. Em sua ética basal, tal cultura, ao menos no que se predica, seria capaz de garantir a integridade poética das obras e sua relação com a história, as táticas expológicas, as nuances do mercado e todos os demais agentes do sistema ${ }^{3}$.

Sendo assim, tal cultura funciona a partir de dispositivos que não terminam nem começam naquilo que classicamente chamamos "projeto curatorial", preocupado a priori com um discurso unificador, modelando expografias, narrativas historiadoras, pedagogias mediadoras e representações midiáticas. A cultura curatorial seria extensiva a todo sistema das artes, para além do design expositivo, ela tornou-se em parte uma força organizadora que empresta, sugere e, às vezes impõem, sua ética selecionadora, confeccionando discursos autorizados que estão, atualmente, baralhados às narrativas da história e da crítica da arte especializadas (SIQUEIRA, 2015). Nesse tocante, nos parece razoável conceber que não há parte do sistema das artes que não demonstre afinidade com tal cultura, incluindo nosso problema: a prática colecionadora. 
É pouco provável que um pesquisador na atualidade negue o impacto das estratégias curatoriais na produção da história da arte, na pedagogia museal ou na organização das práticas de mercado. Como componente a tais processos, a cadeia de colecionamento contemporâneo também se expressa - por meio desta cultura. Ou seja, a formação de coleções de arte contemporânea nas últimas décadas não nos parece imunes ao jogo das estratégias curatoriais ${ }^{4}$. A obra enquanto lugar que dar-se a ver, o que se pensa dela, como ela se deixa ver, onde ela se deixa guardar e de que modo ela se relaciona com aqueles que a produzem e a colecionam, parece-nos tomada pela cultura da curadoria.

Certamente essa visão precária que oferecemos não é o fim da questão. O "curadorismo", expressão cáustica de Waltércio Caldas, é apenas o início, visto a diversidade de dispositivos acionados pela cultura curatorial. De qualquer modo, quando induzimos que os processos de colecionamento contemporâneos são conduzidos e expressos por essa lógica, não estamos dizendo nada de novo. Isso porque tanto curadoria, quanto a coleção, ambas entendidas como discurso e prática, prezam pelo sentido de conjunto; no qual as unidades são percebidas pela sua correlação mútua. Mesmo que nem sempre nos pareçam críveis ou transparentes os valores utilizados para representar tal unidade.

Não como tipo exemplar, mas como motivo interpretativo, tomemos o caso da coleção Figueiredo Ferraz, hoje alocada no Instituto Figueiredo Ferraz, para refletir no como a cultura curatorial no colecionamento contemporâneo. As narrativas sobre a gênese da coleção elegeram o óleo sobre tela de Jorge Guinle de 1981 como ponto de partida. Dispnéia parafernália é a obra matricial nos relatos de João Carlos Figueiredo Ferraz, o principal articulador da coleção. A obra de Guinle foi a primeira peça comprada "na primeira exposição individual do artista em São Paulo, na Galeria Luisa Strina” (QUEMIN; FIALHO; MOARES, 2014, p.176). O colecionador esclarece:

Com o intuito de comprar uma obra de arte para colocar na nossa casa, fui levado por amigos a sua galeria [...]. Não me lembro exatamente qual exposição estava sendo mostrada na época, mas para poder me dar mais opções, inclusive de preço, a Luisa mostrou o que tinha na sua reserva técnica. Era um mundo estranho e delicioso, me lembro de um rolo enorme com telas do Leonilson que ela abria displicentemente, falando que se tratava de um 'artista jovem muito promissor'. 
Tinha em seu acervo tantas telas e tantos nomes que é impossível lembrar. Conversamos bastante, escolhi uma delas, e fui embora. (INSTITUTO FIGUEIREDO FERRAZ, 2015, s.p.)

A primeira exposição de Guinle em São Paulo foi "Passos Diacríticos", em junho de 1982, na Galeria de Luisa Strina. Dispnéia tornou-se a ponta de uma grande coleção de arte contemporânea, que exprime não apenas o gosto do colecionador em relação à produção desde então, mas seu envolvimento com o sistema da arte brasileira. Desde a compra da tela de Guinle até sua exposição em 2011, na mostra inaugural do Instituto Figueiredo Ferraz (IFF), em Ribeirão Preto, podemos facilmente afirmar que a trajetória dos Figueiredo Ferraz, como colecionadores, está intimamente ligada à consolidação do mercado de arte brasileiro, incluindo seus reveses e suas contradições.

\section{Dispnéia e outros sem títulos}

Figura 1.

Residência dos Figueiredo Ferraz. Ao fundo: Jorge Guinle, Dispnéia parafernália, 1981, óleo sobre tela, $152 \times 180 \mathrm{~cm}$.

Fonte: MAM-SP; MAM-RJ, 2001.

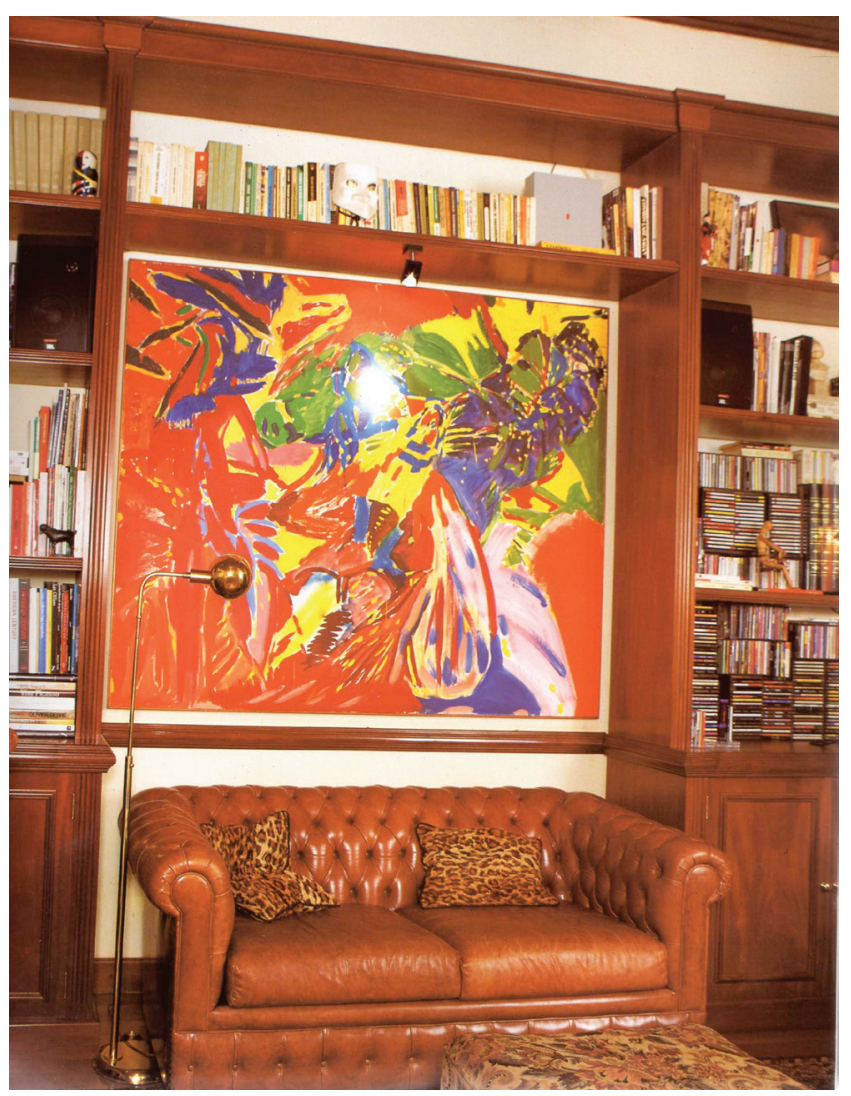


Os critérios que fizeram de Dispnéia a primeira obra da coleção não são necessariamente tangíveis pelas declarações do colecionador. Todavia a aproximação com a geração consagrada na renomada exposição “Como Vai Você, Geração 8o?", realizada na Escola de Artes do Parque Lage, em 1984, sob a curadoria de Marcus Lontra, Paulo Roberto Leal e Sandra Magger, é a primeira característica visível. Além de Guinle, a atual coleção do IFF possui um número considerável de obras dos participantes daquela mostra: Daniel Senise, Cristina Canale, Fernando Barata, Leonilson, Sérgio Romagnolo, Alexandre Dacosta, Elizabeth Jobim, Karin Lambrecht, Ana Maria Tavares, Ester Grispum, Leda Catunda, entre outros. Além deles, outros artistas igualmente cruciais para compreender tal "geração" e ligados à produção paulistana também foram adquiridos pelos colecionadores. Nesse sentido, podemos destacar a presença do notável conjunto de obras dos integrantes da Casa 7 - Fábio Miguez, Paulo Monteiro, Carlito Carvalhosa, Rodrigo Andrade, Nuno Ramos -, que, reunidos entre 1982 e 1985, compartilhavam com Guinle algumas similitudes estéticas. Como nos lembra Ferraz: "eles estavam surgindo na mesma época em que eu começava a colecionar arte. Temos trajetórias semelhantes" (QUEMIN; FIALHO, MORAES, 2014, p.186). Além deles, temos, desta mesma "geração", artistas como Jac Leirner, Fabio Cardoso, Adriana Varejão e Dora Longo Bahia.

Tais artistas foram apostas mais ou menos conscientes de um grupo de galeristas paulistanos ${ }^{5}$, cujo nome de Strina é o mais relevante para o início da coleção do IFF. Para Aracy Amaral a aproximação com a galerista instituiu "uma empatia geracional com os artistas da galeria” (AMARAL, 2014, p. 28), o que guiou suas primeiras compras e caracterizou, até o final dos anos de 1990, a coleção. Para a crítica e historiadora da arte a relação com o mercado primário expressou não apenas o modelo de aquisição, mas uma mudança na relação entre colecionadores e o sistema da arte no Brasil:

A meu ver, sua coleção exala certa busca por elegância, certa unidade na escolha (ao mesmo tempo múltipla), embora para minha geração seja estranho seu não contato direto com os artistas em geral. Mas vejo que João Carlos é parte desta geração que se inicia como colecionador, a partir de um leque amplo de galerias. (FERRAZ, 2014, p.28)

"Elegância" é um atributo genérico, mas expressa com alguma qualidade as relações que marcaram a simbiose dos co- 
lecionadores com o sistema da arte. A presença de galeristas, críticos especializados e curadores em toda a cadeia constitutiva da coleção oferece-nos a possibilidade de verificar um sistema de seleções mediadas que implicaram não apenas na garantia de que a coleção expressasse o "gosto" particular do colecionador, mas, também garantiu que as obras tivessem uma sobrevida nas narrativas dos especialistas, justamente por que os valores que definiram quais obras selecionar eram compartilhados ${ }^{6}$.

Tal sobrevida não é corriqueira. O sistema de galerias tornou-se essencial para a compreensão de como a arte se institui desde o final do século XIX no cenário europeu e, no caso do Brasil, como lentamente tal sistema consolidou-se até o final do século seguinte (RAMOS, 2012). Na segunda metade do século XX, as principais galerias do eixo Rio-São Paulo não apenas exerceram sua tarefa como intermediárias mercantis, como, paulatinamente, foram constituindo-se como espaços expositivos alternativos, organizadores críticos, abrindo-se ao discurso curatorial, publicando e organizando novas abordagens ou revisões da história da arte recente.

De modo sintético, as galerias tornaram-se mediadores importantes na atribulada cena da arte experimental e contemporânea. Ao lado de poucos museus e algumas instituições formadoras, as galerias ajudaram a criar um elenco de colecionadores de arte contemporânea, contribuindo para a formação de seu "olhar" e para assimilação de uma produção que para muitos era hermética e errática.

A seleção dos galeristas diante de uma produção cada vez mais plural alicerçou boa parte do mercado primário de arte nos últimos quarenta anos no Brasil. De um lado promovendo artistas, garantindo-lhes espaços institucionais, tanto na perspectiva do arquivamento ${ }^{7}$, quanto na circulação midiática. Tal arquitetura foi bem-sucedida em suas ambições, pois criou um mercado que, até meados dos anos de 1990, era quase exclusivamente doméstico, com poucas coleções voltadas para a assimilação de artistas estrangeiros. E mais: "Satisfeitos com o potencial dos colecionadores locais, centrados na arte nativa, os agentes de mercado não se mobilizaram para promover a arte moderna e contemporânea produzida no país no circuito internacional" (RAMOS, 2012, p.93).

A coleção do IFF expressa essa correlação. Seguindo a análise de Ana Letícia Fialho para o período dos últimos quarenta $\operatorname{anos}^{8}$, a coleção aponta num primeiro momento uma empatia quase que exclusiva pela arte produzida no Brasil ${ }^{9}$, abrindo- 
-se, nos anos 2000, para fotografia e outras obras contemporâneas de estrangeiros, reflexo do efetivo convívio das galerias e dos colecionadores com as feiras internacionais de arte.

Além da produção da "geração anos 8o", a coleção apresenta um importante conjunto de obras que dialogam com a tradição construtiva brasileira, como é o caso das obras pontuais de Carlos Fajardo, Iole de Freitas, Ivens Machado, Márcia Pastore, Artur Lescher, Nelson Felix, Waltércio Caldas, Eduardo Sued, Jose Resende, Regina Silveira, entre outros. E que, ainda, podem incluir a escultura "O Chicote" (1988) de Ana Maria Tavares, a obra "Ouro e paus: engradados” (1995) de Cildo Meireles e os "Sarrafos" (1987) de Mira Schendel. Além dos artistas diretamente filiados como Amilcar de Castro, Geraldo de Barros e Sérgio Camargo.

As diferentes poéticas adotadas pela pintura dos anos de 1980 e a "herança" construtiva, já amplamente debatida em nossa história da arte recente, caracterizam o conjunto de obras mais perceptíveis naquela que foi a exposição "fundante” na visibilidade da coleção em 2001. “O espírito da nossa época” foi um projeto idealizado por João Carlos Figueiredo Ferraz e foi antecedido por quatro encontros em novembro de 200o. Tais encontros debateram os problemas e as características do colecionismo e a produção da arte contemporânea brasileira $^{10}$. Numa das mesas-redondas João Carlos responde à pergunta de Angélica de Moraes sobre o que motiva um colecionador e quando alguém se descobre colecionador:

[...] Pode-se começar comprando por uma motivação visual: depois se está decorando a casa; e, aos poucos, chega-se num momento em que se tem o primeiro caixote de obras guardado, sem lugar para colocá-las. É um momento em que você se vê realmente colecionando. Mas outro tipo de tomada de consciência da coleção ocorre quando se vem comprando, com alguma regularidade, até que lhe é oferecido um trabalho muito bonito, mas que, por um motivo ou por outro, não se encaixa no leque até então contemplado por suas compras. Então, você abre mão daquela obra, e se percebe, não um comprador diletante, mas um colecionador. (MUSEU DE ARTE MODERNA DE SÃO PAULO; MUSEU DE ARTE MODERNA DO RIO DE JANEIRO, 2001, p.71)

A resposta é paradigmática para instruir-nos o que Ferraz compreende como colecionador: alguém que agrupa um conjunto de obras e que, em algum momento, essas obras 
precisam dialogar entre si. O "comprador diletante", mesmo impulsionado por seu gosto, cede lugar ao articulador. Aquele que assimila uma nova obra tendo as anteriores como parâmetro.

Havia, ainda, outro nível de consciência que estava se materializou com "O espírito da nossa época". Os encontros foram uma antecipação das mostras nos Museus de Arte Moderna de São Paulo e do Rio de Janeiro, realizadas em abril e agosto de 2001, respectivamente. Idealizadas pelo colecionador, com curadoria de Stella Teixeira de Barros, as exposições apresentaram ao público um recorte das obras assimiladas até aquele período. Não se tratava da primeira exposição da coleção. Em 1998, o Museu de Arte de Ribeirão Preto acolheu uma mostra com igual ambição, com curadoria de Agnaldo Farias e montagem de Rubem Breitman. Todavia, tratava-se agora de dois dos mais importantes museus do país, que recebiam não apenas as obras, mas, também, artistas, curadores, críticos, galeristas e o colecionador para debater o lugar do colecionamento no cenário contemporâneo brasileiro. Anos depois, Ferraz admite que:

Foi uma delícia ver que, juntas, elas conversavam, elas tinham muitas afinidades, embora fossem de vários artistas diferentes, com propostas estéticas próprias e compradas em ocasiões as mais diversas. [...] Foi ali que tive a certeza de que tinha mesmo uma coleção, ou seja, um conjunto de trabalhos que fazem um sentido, que dão um testemunho e se constituem em cultura. (QUEMIN; FIALHO; MORAES, 2014, p.187).

As ideias de "testemunho" e "espírito de uma época" são recorrentes nas entrevistas e textos do colecionador. Se há uma ambição para a coleção dos Figueiredo Ferraz - e é difícil dizê-lo quando se trata de uma coleção ainda em construção -, essa pode ser expressa na tentativa de sintetizar uma "época". Ou seja, de apresentar um conjunto que expresse a consolidação da arte contemporânea no Brasil e, depois, no exterior. "O que procuro valorizar é o conhecimento do período em que as obras foram feitas. É entender a obra inserida em um movimento amplo e não apenas como algo de um artista específico." (QUEMIN; FIALHO; MORAES, p. 186).

"O espírito da nossa época" também foi importante por que exemplifica uma mudança no modo como os colecionadores instituem a visibilidade de suas coleções. No dabate sobre o assunto, a curadora da mostra relata: 
Às vezes, um grande colecionador sequer emprestava obras de sua coleção para uma exposição pública. [...] 'É meu, não empresto para ninguém'. Era o mesmo que juntar bolinhas de gude, conchinhas, um tipo de colecionismo quase infantil, que não se dá conta de uma responsabilidade face a um bem cultural. (MUSEU DE ARTE MODERNA DE SÃO PAULO; MUSEU DE ARTE MODERNA DO RIO DE JANEIRO, 2001, p.22)

O que Stella Teixeira de Barros expressa é uma mudança mais ou menos visível a partir dos anos 2000, com colecionadores promovendo exposições de suas coleções, abrindo espaços próprios ou consolidando parcerias e comodatos com instituições museológicas. Nesse tocante, a coleção Figueiredo Ferraz torna-se pragmática com a fundação de seu instituto homônimo. A instituição foi concebida para ser fechada inicialmente, mas abriu-se como um dos espaços obrigatórios para quem quer conhecer parte da produção artística brasileira das últimas décadas.

\section{Espaço aberto, espaço fechado"}

Nos anos seguintes a coleção amplia sua dinâmica formativa, sem, contudo, abandonar as preferências anteriores. Dois grupos de obras são notáveis: as fotografias e as peças que podemos classificar como pertencentes às "poéticas do espaço", melhor dizendo, obras cujas demandas dialógicas com o espaço expositivo exigem bem mais que a condição do espaço doméstico (Figura 1). Daí a necessidade de um espaço institucional mais amplo, que pudesse ver a coleção reunida, pareceu ser o próximo passo.

A constituição do IFF em Ribeirão Preto surgiu desse passo seguinte. Debatida por anos, a ideia original, segundo o colecionador, constituía-se num contrato de comodato com a Pinacoteca do Estado de São Paulo. A coleção passaria para administração e guarda do museu e, em contrapartida, o governo do Estado de São Paulo construiria uma nova sede da Pinacoteca, em Ribeirão Preto, em parceria com a prefeitura da cidade. Mas o projeto não se concretizou. A opção seguinte foi a criação e construção de um espaço próprio, financiado pelos colecionadores e, inicialmente, restrito ao público.

Entre 2010 e 2011, surgiu a sede do IFF com 1.800 metros quadrados de espaço expositivo. Capaz de apresentar um terço das mil obras assimiladas, o edifício apresentava as condições propícias de salvaguarda e comunicação da coleção. A 
abertura, inicialmente não planejada, para o amplo público deu-se com a mostra "O Colecionador de Sonhos", em outubro 2011, com curadoria de Agnaldo Farias. O acervo do IFF já apresentava a guinada em favor da fotografia e de obras "instaladas". Comparada às exposições de 2001, o acervo ganhava em variedade, escala e abria-se para as estratégias educativas e aos dispositivos curatoriais. Farias, por exemplo, reforçava a vocação inicial da coleção nos anos de 1980:

Ele [João Figueiredo Ferraz] já começara a constituir uma respeitável coleção com algumas das melhores obras dos nossos melhores artistas, modernos e contemporâneos; dos jovens que naquela altura enchiam a vista de um Brasil recém saído do marasmo cultural dos anos sombrios e festejavam a abertura política, até artistas maduros, mestres como Eduardo Sued, Amilcar de Castro, Mira Schendel (FARIAS, 2011, on-line).

Como nos anos iniciais, nos anos 2000 as aquisições de obras de uma nova geração de artistas coabitaram com assimilações de artistas já colecionados anteriormente. As obras dependentes da relação com espaço, naquilo que tipificamos como "poéticas do espaço" (instalações, vídeo-instalações, intervenções, site-specifics etc.), passaram paulatinamente a conquistar maior visibilidade dentro da coleção. É certo que desde o início as instalações estavam presentes. Obras instaladas de Jac Leirner, Adriano Pedrosa, Vik Muniz, Tunga e Francis Alÿs são exemplos do interesse dos colecionadores. Mas nos últimos anos, a coleção passou a abrigar aquilo que denominamos como obras "institucionais". Aquelas dependentes de espaços museológicos privilegiados e que raramente são pensadas para ambientes domésticos com escala construtiva padrão.

A construção do IFF, desta forma, abriu a coleção para um novo padrão de obras, cujos regimes de expositividade (POINSOT, 2012) diferem daquela ofertada pela casa dos colecionadores. Trabalhos como "Quando tudo fica mais claro" de Nelson Felix, uma instalação de 2012 que exige a perfuração de uma parede, dividindo a obra em dois ambientes; ou "Metade da fala no chão - piano surdo", uma instalação, resíduo de uma performance delegada, de Tatiana Blass de 2010, com cera microcristalina no chão sob um piano de calda que "contamina" o espaço de exposição; e, mesmo, o jogo ilusionista de Marcius Galan em "Secção diagonal", de 2011, onde 
o próprio espaço expositivo alterado (cor das paredes e iluminação) constitui a obra. Mesmo trabalhos materialmente independentes cresceram em volume e dimensões como é o caso de "Shackelton 1" de Nuno Ramos, uma estrutura de madeira laminada e areia comprimida de 150 x 470 x $60 \mathrm{~cm}$; ou a escultura "Sem título" de Iole de Freitas de 2011, uma peça de aço inox e policarbonato de $300 \times 780$ x $470 \mathrm{~cm}$.

Se é temeroso associar a mudança na seleção das obras diante das novas condições expositivas, igualmente o é quando subestimamos uma mudança como esta: obras colecionadas para ambientes domésticos e obras colecionadas para espaços institucionais. E a questão não é apenas a altura entre o piso e teto do ambiente. Diante de um amplo público, colocadas, lado a lado, em exposições de durações diversas as obras passaram a ser compreendidas dentro do funcionamento sócio-simbólico da exposição. Táticas curatoriais, estratégias museográficas e a arquitetura expositiva foram alçados para garantir alguma unidade semântica da coleção. Além disso, a assimilação de obras como instalações, intervenções e vídeos ampliou a coleção na direção das linguagens que são facilmente associadas às mudanças propostas pela pelas experimentações da arte contemporânea.

Concomitantemente a fotografia torna-se mais presente. De nomes consagrados no cenário brasileiro a artistas estrangeiros, ainda, pouco conhecidos no Brasil, o IFF investiu na assimilação da fotografia expressiva, na divulgação de outras coleções fotográficas e na segmentação do espaço expositivo, geralmente, dedicado à linguagem. Não se trata apenas da fotografia em sua materialidade convencional, mas, também combinada a outros suportes, como parte de projetos poéticos amplos (como no caso da fotoperformance) e apresentada em contextos híbridos e matrizes digitais.

O número é expressivo. Obras de Massao Yamamoto, Michael Wesely, Janaina Tschäpe, Nicola Constantino, Brigida Baltar, Patricia Osses, Gordan Manic, Claudio Edinger, Albano Afonso, Marcio Banfi, Cristián Silva-Avária, Ignacio Llamas, Caio Reisewitz, Rubens Mano entre outros. Destacam-se a fotografia enquanto componente de obras como "Maleta" do espanhol Chema Alvargonzalez de 2011, e o "Sem título" de Fernando Vilela, híbrido entre fotografia e gravura, de 2012; apenas para citar as obras mais recentes que se alinham a fotografias adquiridas anteriormente. Recentemente, em maio de 2015, o IFF apresentou a exposição "O Espírito de Cada Época”, com curadoria de Rejane Cintrão, 
que segmentou por décadas a produção assimilada pelos colecionadores, tipificando as principais características de cada período. Sobre os anos 200o, Cintrão reforça a predileção pela imagem fotográfica: "Os artistas começam a utilizar cada vez mais a fotografia como meio de expressão, buscando novas formas e poéticas para essa estética" (INSTITUTO FIGUEIREDO FERRAZ, 2015).

Figura 2.

Instituto Figueiredo Ferraz, vista da exposição "Além da forma: plano, matéria, espaço e tempo", curadoria Cauê Alves, 2012, Ribeirão Preto, SP.

Fonte: Folder da exposição.

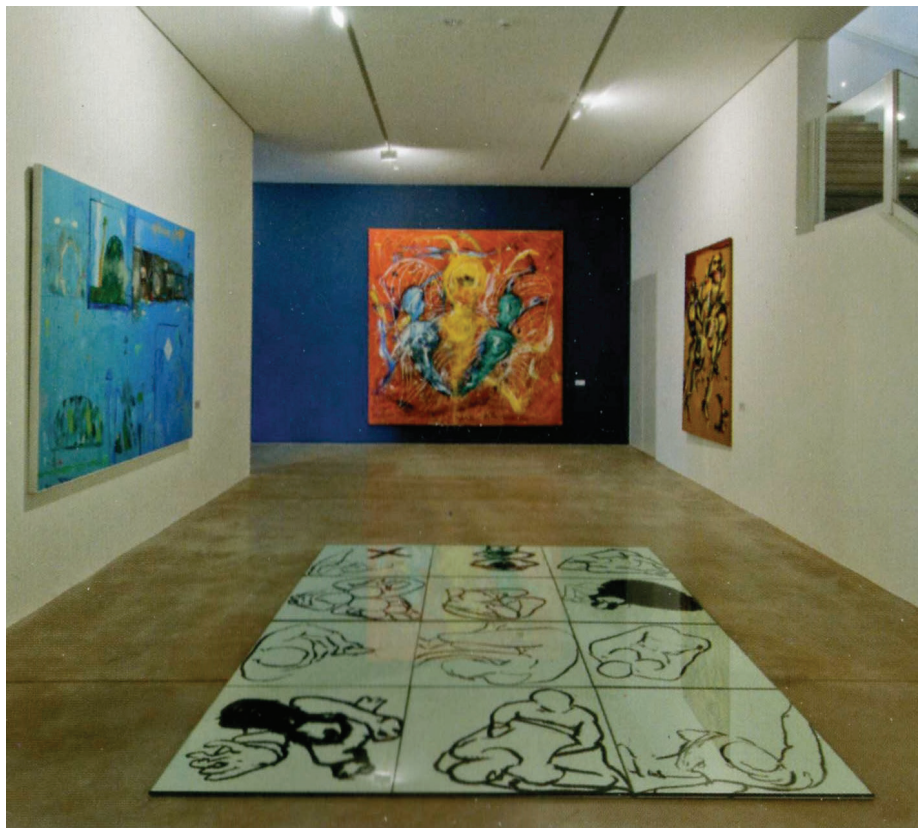

O ciclo que liga a produção contemporânea dos últimos anos adquirida pelos Figueiredo Ferraz a Dispnéia parafernália, de Guinle ganhou nexo com o projeto curatorial "O Espírito de Cada Época”. A exposição de 2015 "repõe”, a seu modo, os valores da exposição "O espírito da nossa época”. Este e outros projetos curatoriais assinados por Daniela Bousso, Agnaldo Farias, Cauê Alves, Maria Alice Milliet, Paulo Venâncio Filho e pela equipe do Instituto consolidaram a coleção como uma pretensa síntese da produção dos últimos trinta anos.

Nesse aspecto as mostras "Além da forma: plano, matéria, espaço e tempo", com curadoria de Cauê Alves, de abril de 2012, e "As tramas do tempo na arte contemporânea: Estética ou Poética?", curadoria de Daniela Bousso, um ano depois, mostra-nos estratégias discursivas próprias da cultura 
curatorial que simultaneamente: abrem a coleção para novas intepretações, mediante as recentes aquisições; celebram os primeiros anos da coleção, em especial, a pintura dos anos de 1980 e; vinculam a coleção às genealogias da arte moderna, com problemas estéticos precisos. No último ponto, Alves (2012) lança mão de problemas estéticos pertinentes à inflexão entre arte moderna e contemporânea, desde os anos de 1950, para balizar seu projeto: "Questão central é o que está no intervalo entre plano, matéria, espaço e tempo. Interessa tanto as virtualidades do plano, quanto a efetividade dos objetos e a sua própria duração, mas principalmente o que se dá entre o sujeito e os trabalhos de arte: a experiência" (ALVES, 2012, s.p.). Tomada como mote, a "experiência" torna-se um elo decisivo para os "diálogos e parentescos entre distintos suportes tais como pintura, fotografia, desenho, objeto, livro, relevo, escultura e instalação" (ALVES, 2012, s.p.). Um unificador das diferentes linguagens e poéticas da coleção.

Já Bousso (2013) interpreta a coleção como índice, alinhavando-a à história da arte moderna: "Esta mostra evidencia múltiplas formas de leitura possíveis na coleção. Ela acolhe diferentes modos da expressão contemporânea, em diálogo aberto com a tradição do Modernismo, entre a década de 1980 e a atualidade pós-virada de milênio" (BOUSSO, 2013, s.p.). Ela elege três núcleos para construir sua curadoria, enfatizando a herança construtiva, uma filiação à poética surrealista e seus desdobramentos e, por último, as formas neobarrocas, "formas orgânicas, oceânicas" (BOUSSO, 2013, s.p.).

De alguma forma, tanto Alves (2012) quanto Bousso (2013) introduzem uma nova perspectiva para uma coleção que busca ser parte de seu "tempo", sua "época". De alguma forma, mesmo de modo involuntário, os curadores apresentam a ideia de que ser contemporâneo, a partir da coleção do IFF, é revisitar os problemas constitutivos que ligam e separam a produção modernista de sua sucessora. $\mathrm{O}$ mesmo não ocorre na recente mostra "O Estado da Arte" ${ }^{12}$. Nela, a curadora Maria Alice Milliet elenca três ideias importantes para a visibilidade da coleção. Em seu texto, Milliet (2012) expressa que a coleção não é dedicada "exclusivamente aos nomes consagrados pelo mercado" (2016). A multiplicidade e heterogeneidade também são salientados, negando-se a compor uma seleção "por técnicas ou temas". Mas, a mais importante ideia defendida pela curadora é a atualidade da coleção, mais uma vez prefigurado à sua época, a sua capacidade de vincular-se à liberdade de expressão: 
No plano ou no espaço, usando meios tradicionais como o desenho ou a pintura, ou alternativos como a fotografia, o vídeo e a instalação, a arte contemporânea é indissociável do presente. Um tempo sem ordem, sem propósito, sem limites. Daí a ousadia de criar com os mais diversos materiais, de promover combinações inusitadas, de suscitar estranhamento. Em nossa época, o belo deixou de ser inerente à criação artística. Entretanto, a beleza irrompe em certas obras. Há trabalhos que nos levam a refletir e outros que nos fazem sonhar. Ao depararmos com essa pluralidade de manifestações, raramente ficamos indiferentes. Muitas vezes, temos a sensação de estarmos diante de algo que não compreendemos plenamente. A capacidade de desestabilizar certezas é a qualidade maior da arte contemporânea cuja força de atração reside em sua conexão com a realidade. (MILLIET, 2012, on-line)

Tanto a curadoria de Milliet (2012), quanto os demais projetos curatoriais funcionam como dispositivos dedicados à produção de um discurso unificador, modelando expografias, narrativas historiadoras e representações midiáticas. Nesse tocante, a exposição de 2014, intitulada "Momento contemporâneo", sob curadoria de Paulo Venâncio Filho, atenta para íntima relação entre o colecionamento e a curadoria. Em seu texto ele acaba por compor um paralelo entre o colecionamento, marcado por processo de seleção, e a curadoria. Paralelismo que afeta o próprio trabalho do curador, pois: "Desta convergência resultou a unidade e coerência da exposição; uma escolha reafirmando a outra: a do colecionador sobre a do curador, e a do curador sobre a do colecionador. Deu-se uma curadoria em segundo grau, por assim dizer." (VENÂNCIO FILHO, 2014).

De um modo efetivo, como poucas no Brasil, a coleção do IFF indicia o complexo jogo do sistema da arte contemporânea atual com suas tensões, estratégias e representações. E nesse tocante, certamente, expressa parte de nossa época. $\mathrm{Na}$ medida em que incorpora nos jogos interpretativos, operados pelos curadores e pelo colecionador, um processo contínuo de vínculo entre a história da arte contemporânea recente e a coleção, vista por sua unidade retrospectiva e amparada por uma fina relação com o mercado da arte. 
1 "O espírito da nossa época" é o título da exposição realizada em 2001, no Museu de Arte Moderna de São Paulo, da coleção aqui analisada. Este texto é fruto de pesquisa financiada pelo $\mathrm{CNPq}$, o que possibilitou as visitas ao IFF nos meses de abril e outubro de 2014 e julho de 2015.

2 Alguns dos textos que apoiam o artigo podem são bons exemplos. Mas, de fato, a literatura sobre o assunto não cessa de se avolumar, em especial, oriunda das práticas artísticas, dos processos mediadores e das ações mercadológicas.

3 A cultura se torna mais efetiva, senão eficiente, quando opera de modo reflexivo. Terry Smith (2012) defende que toda curadoria deve propor sua reavaliação crítica. Uma "recuradoria" como forma de produzir novos argumentos e novas estratégias para o trabalho do curador.

4 Refletindo sobre o papel do curador no sistema das artes Elaine Caramella (2014, p.35) escreve: "O curador seria o elo entre a legitimação cultural e legitimação de mercado. O elo do curador com o investidor, patrocinador, galeristas, colecionadores, outros curadores, mídia, etc. é indispensável, bnem que seja para promover aquele artista que já está inserido num contexto de crítica consensual."

5 João Figueredo Ferraz destaca a relevância de outros galeristas na constituição de sua coleção: Marcantonio Vilaça, Raquel Arnaud, João Sattamini, Rubem Breitman, Fernando Milan, Marília Razuk, Alessandra e Márcia Baró, Bel Pinheiro, Eliana Brandão, Marcelo Guarnieri, entre outros. (FERRAZ, 2014, p. 34).

$6 \mathrm{Na}$ ocasião da abertura da exposição "Afinidades - Raquel Arnaud 40 anos", em homenagem à galerista, João Figueiredo Ferraz declarou: "A Raquel sempre me impressionou pela coerência e rigor na escolha dos artistas com quem trabalha. Sua escolha, ao longo do tempo, nos mostra o quanto este olhar é correto e certeiro." VARELLA, Paulo. Arte.ref. Instituto Figueiredo Ferraz homenageia Raquel Arnaud com exposição "Afinidades". 2014. Disponível em: <http://arteref.com/diversos/instituto-figueiredo-ferraz-homenageia-raquel-arnaud-com-exposicao-afinidades-raquel-arnaud40-anos/>. Acesso em: nov. 2015.

7 A ação é usual. Inúmeras Galerias de Arte em todo o Brasil realizaram doações para instituições museológicas públicas (OLIVEIRA, 2014).

8 Ao refletir sobre as condições de internacionalização da arte brasileira, Fialho escreve "É interessante observar que, apesar de se tratar de uma história muito recente, é possível identificar, pelo menos, duas fases bastante distintas nesse processo: a primeira se situa entre o final dos anos de 1980 e começo dos anos de 1990, quando ocorre uma renovação controlada da oferta (MOULIN, 200o), com uma expansão de fronteiras do mapa das artes a partir do centro e com foco na produção artística, e a fase atual, que se inicia no final da década de 1990 e ainda, se encontra em curso, na qual observamos o início de uma descentralização dos circuitos de legitimação." Sobre a segunda fase, a autora completa em nota: "Ocorre uma expansão do campo institucional (espaços de arte contemporânea, bienais e equivalentes), uma diversificação do pensamento sobre a arte contemporânea (incluindo práticas curatoriais, publicações, pesquisas acadêmicas) e uma diversificação dos agentes que atuam no mercado (galerias e colecionadores de regiões não centrais passam a participar do jogo intencional). (FIALHO, 2012, p.143)

9 As exceções existem e são recorrentemente lembradas pelo material institucional do IFF. Obras de Alfredo Jaar, Antoni Muntadas, Pedro Cabrita Reis, Doris Salcedo, Francis Alÿs, entre outros.

10 No formato de mesa-redonda, os encontros foram realizados no auditório 
do Museu de Arte Moderna de São Paulo, cujas configurações foram: Mesaredonda 1 (o6 de novembro de 200o) com a presença dos artistas Iran do Espírito Santo, José Resende e Leda Catunda, do curador Ivo Mesquita e da galerista Karla Camargo; Mesa-redonda 2 (13 de novembro de 2000) com a presença da jornalista Angélica de Moraes, da galerista Raquel Arnaud e dos artistas Dudi Maia Rosa e Fábio Miguez, Paulo Pasta; Mesa-redonda 3 (21 de novembro de 2000) com a presença do curador Agnaldo Farias, dos artistas Paulo Monteiro e Iole de Freitas; Mesa-redonda 4 (27 de novembro de 2000) com a presença dos artistas Jac Leirner, Nuno Ramos e Waltércio Caldas, da galerista Luisa Strina. Todos os encontros foram mediados pela curadora Stella Teixeira de Barros e tiveram a presença do colecionador. (MUSEU DE ARTE MODERNA DE SÃO PAULO; MUSEU DE ARTE MODERNA DO RIO DE JANEIRO, 2001)

11 Título de obra fotográfica de Rubens Mano, de 2002, pertencente à coleção do IFF.

12 Aberta no dia 19 de março de 2016.

\section{Referências}

ALVES, Cauê. Além da forma: plano, matéria, espaço e tempo. Texto de divulgação da exposição. Instituto Figueiredo Ferraz. 2012. Disponível em: < http://www.iff.art.br/exposicoes/alem-da-forma/>. Acesso em: 16 jan. 2016.

AMARAL, Aracy. Colecionismo de arte no Brasil: uma nova geografia no Estado de São Paulo. In: FERRAZ, João Carlos de Figueiredo. Instituto Figueiredo Ferraz. São Paulo: SGFF Editorial, 2014. p. 21-31

BOUSSO, Daniela. As tramas do tempo na arte contemporânea: estética ou poética? Texto de divulgação da exposição. Instituto Figueiredo Ferraz. 2013. Disponível em: http:// www.iff.art.br/exposicoes/estetica-ou-poetica/. Acesso em 16 de janeiro de 2016.

CARAMELLA, Elaine. O sistema das artes como pedágio para legitimação do valor artístico: a esfera da legitimação cultural. In: ; ARANTES, P.; BARRETO, S. R. (Org.). Arte: história, crítica e curadoria. São Paulo: Educ/PUCSP, 2014. p. 23-39.

FARIAS, Aguinaldo. O Colecionador de Sonhos. Texto de divulgação da exposição. Instituto Figueiredo Ferraz. 2011. Disponível em: <http://www.iff.art.br/exposicoes/o-colecionador-de-sonhos/>. Acesso em: 16 jan. 2016.

FERRAZ, J. C. Instituto Figueiredo Ferraz. São Paulo: SGFF Editorial, 2014.

FIALHO, A. L. O Brasil está no mapa? Reflexões sobre a inserção e a visibilidade do Brasil no mapa internacional das artes. In: RAMOS, M.L.B. (Org.) Sociologia das artes visuais no Brasil. São Paulo: Editora Senac, 2012. p.141-16o. 
GEORGEL, C. O colecionador e o museu, ou como mudar a história da arte? Tradução Ana Cavalcanti. Revista Museologia e Interdisciplinaridade, v. 3, n. 6, p.277-286, mar./abr. 2015.

GLICENSTEIN, J. L'invention du curator. Paris: Presses Universitaires de France, 2015.

INSTITUTO FIGUEIREDO FERRAZ. O Espírito de cada época. Folder de divulgação de exposição. Ribeirão Preto; 2015.

LOPES, A. A reversibilidade do tempo na pintura de Jorge Guinle. Palindromo, v.2, n. 3, p.117-143, 2010.

MADZOSKI, Vesna. A invenção dos curadores. Arte $\mathcal{E}$ Ensaios, n. 28, p.145-165, dez. 2014.

MILLIET, M. A. O estado da arte. Texto de divulgação da exposição. Ribeirão Preto: Instituto Figueiredo Ferraz, 2012. Disponível em: <http://www.iff.art.br/exposicoes/o-estado-da-arte/>. Acesso em: 04 mar. 2016.

MUSEU DE ARTE MODERNA DE SÃO PAULO; MUSEU DE ARTE MODERNA DO RIO DE JANEIRO. O Espírito da nossa época. Catálogo de exposição. Curadoria de Stella Teixeira de Barros. São Paulo; Rio de Janeiro: MAM-SP; MAM-RJ, 2001.

OLIVEIRA, E.D. Algo familiar: considerações sobre as doações em museus de arte brasileiros". Musas, Revista Brasileira de Museus e Museologia, n. 6, p. 76-90, 2014.

POINSOT, J. M. A arte exposta: o advento da obra. In: HUCHET, S. (Org.). Fragmentos de uma teoria da arte. São Paulo: Edusp, 2012. p. 141-184.

QUEMIN, A.; FIALHO, A.L.; MORAES, A. O Valor da obra de arte. São Paulo: Metalivros, 2014.

RAMOS, M. L. B. O mercado de arte no Brasil em meados do século XX. In: (Org.) Sociologia das artes visuais no Brasil. São Paulo: Editora Senac, 2012. p. 75-95.

SIQUEIRA, V. B. C. Curadoria como tarefa crítica. In: ENCONTRO DA ANPAP, 24, 2015, Santa Maria, RS. Anais... Santa Maria, RS: Anpap, 2015. p. 3896-3902.

SMITH, Terry. Thinking Contemporary Curating. Nova York: Independent Curators Internacional, 2012.

VENÂNCIO FILHO, P. Momento contemporâneo. Texto de divulgação da exposição. Ribeirão Preto: Instituto Figueiredo Ferraz, 2014. Disponível em: <http://www.iff.art.br/exposicoes/momento-contemporaneo/>. Acesso em: mar. 2016. 
Recebido em: 02/05/2016

Aceito em: 08/o6/2017

\section{EMERSON DIONISIO GOMES DE OLIVEIRA}

dionisio@unb.br

Historiador da arte vinculado aos programas de Pós-graduação em Arte e de Pós-graduação em Ciência da Informação, ambos da Universidade de Brasília. Membro dos Grupo de Pesquisa "História da Arte: modos de ver, exibir e compreender" e do Grupo de Pesquisa "Museologia, Patrimônio e Memória". Editor da Revista VIS (PPGArte) e da Revista Museologia e Interdisciplinaridade (PPGCinf). 